\title{
Clinical Benefit of Insulin Glargine 300 U/mL Among Patients with Type 2 Diabetes Mellitus Previously Uncontrolled on Basal or Premixed Insulin in Serbia: A Prospective, Observational, Single-Arm, Multicenter, Real-World Study
}

\author{
Milena Velojic-Golubovic • Vojislav Ciric · Marija Dimitrijevic • Tijana Kovic • Milica Mitic • \\ Biljana Olujic $\cdot$ Natasa Pevac Sasa Radenkovic $\cdot$ Danijela Radojkovic Selena Vukadinovic \\ Djordje S. Popovic
}

Received: March 3, 2021 / Accepted: May 6, 2021 / Published online: June 23, 2021

(c) The Author(s) 2021

\begin{abstract}
Introduction: Insulin glargine $300 \mathrm{U} / \mathrm{mL}$ (Gla300 ) is a novel glargine formulation which shows slower and more prolonged absorption following subcutaneous administration in comparison to insulin glargine $100 \mathrm{U} / \mathrm{mL}$. In this prospective, observational, single-arm, multicenter, real-world study conducted in Serbia, we evaluated the effectiveness and safety of Gla-300 in patients with type 2 diabetes mellitus (T2DM) previously inadequately controlled with different basal or premix insulin therapy regimes.
\end{abstract}

M. Velojic-Golubovic · V. Ciric · S. Radenkovic ·

D. Radojkovic $\cdot$ S. Vukadinovic

Clinical Center Nis, Nis, Serbia

M. Velojic-Golubovic · V. Ciric - S. Radenkovic .

D. Radojkovic

Medical Faculty, University of Nis, Nis, Serbia

M. Dimitrijevic · T. Kovic

Sanofi, Belgrade, Serbia

M. Mitic

General Hospital Cuprija, Cuprija, Serbia

B. Olujic

General Hospital "Dr Radivoj Simonovic", Sombor, Serbia

N. Pevac

General Hospital Sremska Mitrovica, Sremska

Mitrovica, Serbia
Methods: A total of 350 patients with T2DM were enrolled by 27 physicians, from date of the first patient in (12 December 2017) to the date of last patient completed/last patient out (30 October 2018), from both medical centers and general hospitals. Patients' observation and data collection were performed at visit 1 (V1), i.e., the inclusion visit (3-6 months after Gla-300 introduction), including collection of retrospective data from the patients' medical charts at the time of Gla-300 introduction, and at visit 2 (V2) (3-6 months after V1). The primary objective was to assess the change in glycated hemoglobin (HbA1c) level from day of the Gla-

D. S. Popovic

Medical Faculty, University of Novi Sad, Novi Sad, Serbia

D. S. Popovic $(\bowtie)$

Clinic for Endocrinology, Diabetes and Metabolic Disorders, Clinical Center of Vojvodina, Hajduk Veljkova 1, 21000 Novi Sad, Serbia

e-mail: pitstop021@gmail.com; djordje.popovic@mf.uns.ac.rs; djordje.popovic@kcv.rs 
300 initiation to the end of the observational period, while the secondary objectives included other effectiveness, as well as safety and other clinically relevant data.

Results: The mean age of the 350 patients was $63.4 \pm 8.4$ years and $56.3 \%$ were female. The mean duration of diabetes was $13.4 \pm 7.4$ years, while the mean duration of insulin therapy prior to Gla-300 initiation was $5.3 \pm 3.9$ years. There was a significant reduction in HbA1c level at each visit compared to the previous visit $(8.63 \pm 1.52 \%$ at baseline prior to Gla-300 initiation, $7.87 \pm 1.13 \%$ at $\mathrm{V} 1,7.45 \pm 1.05 \%$ at V2; $p<0.01$ vs. previous visit) accompanied by significant reduction of all hypoglycemic events $(p<0.01)$.

Conclusion: Initiation of Gla-300 therapy significantly improved glycemic control and reduced the risk of hypoglycemia in patients with T2DM inadequately controlled with different basal or premix insulin therapy regimes. Funding: Sanofi Serbia.

Keywords: Basal insulin; Glargine 300 U/mL; Glycemic control; Type 2 diabetes

\section{Key Summary Points}

Insulin glargine $300 \mathrm{U} / \mathrm{mL}$ is a novel glargine formulation which shows slower and more prolonged absorption following subcutaneous administration in comparison to insulin glargine $100 \mathrm{U} / \mathrm{mL}$

We evaluated the effectiveness and safety of insulin glargine $300 \mathrm{U} / \mathrm{mL}$ in patients with type 2 diabetes mellitus previously inadequately controlled with different basal or premix insulin therapy regimes

The primary objective was to assess the change in glycated hemoglobin level from day of the insulin glargine $300 \mathrm{U} / \mathrm{mL}$ initiation to the end of the observational period
There was a significant reduction in glycated hemoglobin level at each visit compared to the previous visit accompanied by significant reduction of all hypoglycemic events

Initiation of insulin glargine $300 \mathrm{U} / \mathrm{mL}$ therapy significantly improved glycemic control and reduced the risk of hypoglycemia in patients with type 2 diabetes mellitus inadequately controlled with different basal or premix insulin therapy regimes

\section{DIGITAL FEATURES}

This article is published with digital features, including a summary slide to facilitate understanding of the article. To view digital features for this article go to https://doi.org/10.6084/ m9.figshare.14541735.

\section{INTRODUCTION}

The intensive antihyperglycemic treatment resulting in reduction of glycated hemoglobin (HbA1c) level delays both the development and progression of complications in patents with type 2 diabetes mellitus (T2DM) [1]. In spite of unambiguous evidence supporting the vital role of optimal glycemic control in the management of patients with T2DM, and increasing number of available pharmacologic options [2], a significant proportion still fail to achieve optimal glycemic targets resulting in a higher risk of diabetes-related morbidity and mortality [3].

Although the number of available antihyperglycemic pharmacologic agents is continuously growing, insulin remains the most effective and consistent treatment for maintaining optimal blood glucose levels in patients with T2DM [4]. However, the risk of hypoglycemia and weight gain are the main limiting factors for justified and timely initiation and optimization of insulin therapy [5-7], often 
preventing both patients and physicians from adequate intensification of the treatment of blood glucose necessary to achieve recommended HbA1c targets [8-10].

Insulin glargine $300 \mathrm{U} / \mathrm{mL}$ (Gla-300) is a novel insulin glargine formulation which shows a slower and more prolonged absorption following subcutaneous administration in comparison to insulin glargine $100 \mathrm{U} / \mathrm{mL}$ (Gla-100), resulting in more even pharmacokinetic and pharmacodynamic profiles, more prolonged duration of action, and extended tight blood glucose control well beyond $24 \mathrm{~h}$ [11].

In EDITION 2, a 6-month, open-label, randomized controlled trial, Gla-300 demonstrated similar glucose-lowering effects with the less frequent nocturnal or severe hypoglycemic episodes during the first 8 weeks of the study, a period when titration should be the most intensive, in comparison to Gla-100 in patients with T2DM [12]. Also, fewer cases of both nocturnal and any time hypoglycemic events and less weight gain were reported over the entire 6-month period for Gla-300 comparing to Gla100 [12].

The aim of this prospective, observational, single arm, multicenter, real-world study, carried out in Serbia, is to evaluate the effectiveness and safety of Gla-300 in patients with T2DM inadequately controlled with different basal or premix insulin therapy regimes.

\section{METHODS}

\section{Study Population}

A total of 27 physicians from both medical centers and general hospitals participated in the study through their involvement in enrolling and following patients throughout 2017 and 2018 (from the date of first patient in on 12 December 2017 to the date of last patient completed/last patient out on 30 October 2018). The selection of patients was done through consecutive recruitment by participating physicians. Each site was expected to enroll 5-25 consecutive patients that have been treated with Gla-300, according to the suitable sample size evaluation revealing that 350 patients have to be included in the study to allow an appropriate country-level analysis. This number of patients were finally included in the study based on the following inclusion criteria: signed patient informed consent, T2DM diagnosis, age 18 years or older, Gla-300 therapy lasting for more than 3 and less than 6 months, and completed patient diary with specific information on insulin dosage and hypoglycemic events recorded in the last 3 months as per usual clinical practice; and exclusion criteria: type 1 diabetes mellitus diagnosis, age below 18 years, start of insulin within 1 year after diabetes diagnosis in patient under 40 years of age, pregnancy or breast-feeding at inclusion, treatment with any systemic corticosteroid, and participation in some other study.

\section{Ethics Approval}

The study was approved by the Ethics Committees and Regulatory authority in Serbia, and all procedures were in accordance with the ethical standards of the 1964 Helsinki Declaration and its later amendments or comparable ethical standards. All the participants provided written informed consent to include their information in anonymous, aggregated analyses for this study.

\section{Data Collection and Measurements}

Patients' observation and data collection were performed twice for each patient, at visit 1 (V1) (inclusion visit), and at visit 2 (V2) (3-6 months after inclusion visit, which represents the next clinical visit in line with routine clinical practice). At V1 both retrospective (the day of Gla300 initiation) data on baseline values and prospective (3-6 months after the Gla-300 initiation) data were collected. The retrospective data included those collected from patient medical charts at the time of the Gla-300 therapy introduction encompassing anthropometrical parameters, previous and current antidiabetic therapy (including details of the previous basal or premixed insulin therapy regime), HbA1c and fasting plasma glucose (FPG) (the most recent value available at the 
time prior to the Gla-300 initiation), fasting self-measured blood glucose (SMBG) (last three available values at the time prior to the Gla-300 initiation), physician reason to start Gla-300 (i.e., patient not reaching $\mathrm{HbA1c}$ target, repeated documented hypoglycemia episodes, etc.), Gla-300 insulin therapy (starting dose), individual HbA1c target, recommendation for Gla300 titration algorithm (frequency, dose increments, and fasting SMBG), and history of severe, symptomatic, verified symptomatic, and nocturnal hypoglycemia within the last 3 months prior to the Gla-300 initiation as documented in the patient diary. These data represent characteristics/values of patients defined as baseline data. The prospective data included dates of examination and signed inform consent, age, gender, anthropometrical parameters, medical history, history and evolution of diabetes, diabetes complications, concomitant diseases, current antidiabetic therapy including any modifications, current Gla-300 basal insulin therapy, HbA1c, FPG, fasting, SMBG (last three available values), occurrence of hypoglycemia from time when Gla-300 was initiated, as well as other adverse events (AE). At V2, anthropometrical parameters, the current antidiabetic therapy (including any modification of the antidiabetic therapy), current Gla-300 basal insulin therapy (if Gla-300 is discontinued before or at V2, the reason for discontinuation and most recent $\mathrm{HbA1c}$ value before discontinuation), HbA1c, FPG, fasting SMBG (last three available values), an occurrence of hypoglycemia from the last visit, and other $\mathrm{AE}$ were noted.

\section{Statistical Analysis}

All variables are presented as continuous data (scale) or categorical (nominal and ordinal). Levene's test was used to assume the equality of variances, while distribution of variables was tested with Kolmogorov-Smirnoff test. Continuous data are presented as mean values with standard deviations, while categorical data are presented with percentages. In the statistical processing of data, paired sample Student's $t$ test, Wilcoxon signed ranks test, and binary logistic regression (enter model) were used. In all tests, alpha level at $0.05(p<0.05)$ was considered to be a statistically significant.

\section{Objectives}

The primary objective of this study was to assess the change in HbA1c from first day of Gla-300 initiation to the end of the observational period.

The secondary objectives included proportion of patients with T2DM reaching HbA1c goal $<7.0 \%$, individual HbA1c target set by physician, and FPG in the range of 4.4-7.2 $\mathrm{mmol} / \mathrm{l}$; changes in fasting SMBG, body weight, and Gla-300 dose, proportion of patients requiring addition of prandial insulin, as well as reasons for changing to Gla-300, and identification of the most frequently used Gla-300 titration algorithm. Finally, occurrence of AE/ serious $\mathrm{AE}$ and hospitalizations due to consequence of T2DM apart from hypoglycemia, and incidence of the hypoglycemic events (any symptomatic, severe, documented symptomatic, and nocturnal) were also analyzed.

\section{RESULTS}

Among 350 enrolled patients with T2DM, $56.3 \%$ were female, and the mean age was $63.4 \pm 8.4$ years. The mean duration of diabetes was $13.4 \pm 7.4$ years. A family history of T2DM has been detected in $61.1 \%$ of patients.

The mean body weight (BW) at baseline was $87.1 \pm 15.9 \mathrm{~kg}$, while the mean waist circumference (WC) was $103.0 \pm 12.9 \mathrm{~cm}$. The mean body mass index (BMI) was $30.4 \pm 5.7 \mathrm{~kg} / \mathrm{m}^{2}$ with $47.7 \%$ of patients being classified as obese. The mean duration of insulin therapy prior to the Gla-300 initiation was $5.3 \pm 3.9$ years. The majority of patients were treated with basal/ bolus or basal plus, basal only, or premixed only therapy, while other insulin therapy regimes were less frequent (Fig. 1a). At baseline, all patients used oral antidiabetic drugs (OAD) for the mean duration of $8.4 \pm 6.3$ years, with metformin as the most frequently prescribed $\mathrm{OAD}$, following sulfonylurea preparations and 
A

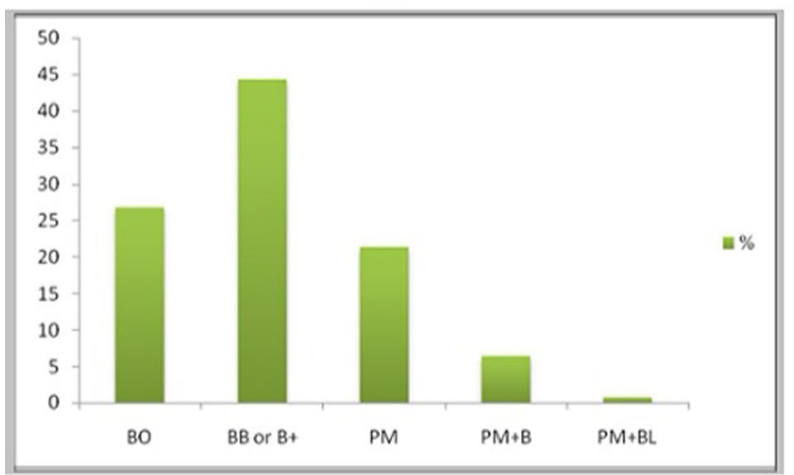

Fig. 1 Antidiabetic treatment at baseline. a Proportion of patients using different insulin therapy regimes at baseline. $\mathrm{BO}$ basal only, BB basal/bolus, $\mathrm{B}+$ basal plus, $\mathrm{PM}$ premix only, $\mathrm{PM}+\mathrm{B}$ premix plus basal, $\mathrm{PM}+\mathrm{BL}$ premix plus

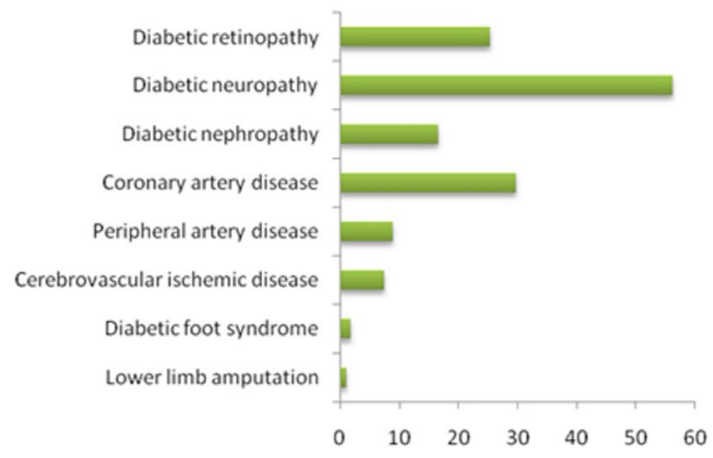

Fig. 2 Proportion of patients with different diabetic complications at inclusion

other OAD (mainly sodium-glucose cotransporter 2 (SGLT2) inhibitors) (Fig. 1b).

Diabetes complications were reported among $76.6 \%$ of patients at inclusion, with diabetic neuropathy as the most frequent complication (Fig. 2). Comorbidities in the form of hypertension and dyslipidemia were present in $90.0 \%$ of patients (hypertension in $81.4 \%$ and dyslipidemia in $76.6 \%$ ).

As far as the primary endpoint of the study is concerned, there was a significant reduction in HbA1c level from baseline (HbA1c value at Gla300 initiation collected retrospectively from patients' medical charts) to HbA1c level at V2 as well as at each visit in comparison to the previous one. Namely, HbA1c values were significantly lower at V1 in comparison to baseline,
B

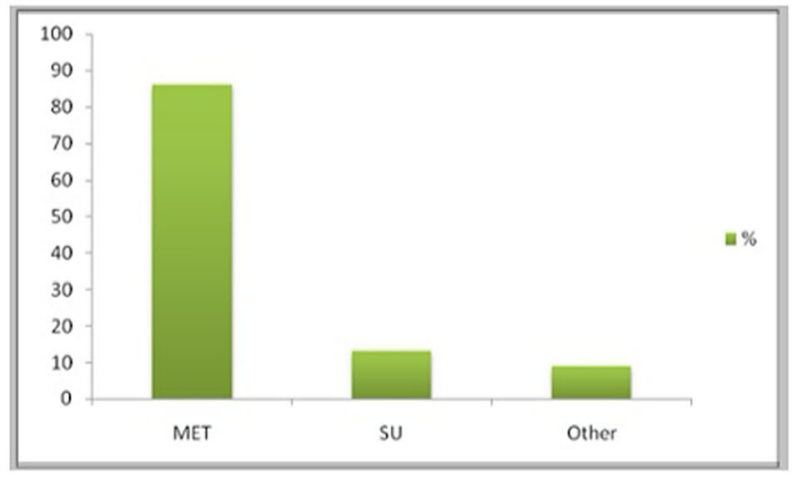

bolus. b Proportion of patients using different oral antidiabetic drugs at baseline. MET metformin, SU sulfonylurea preparations

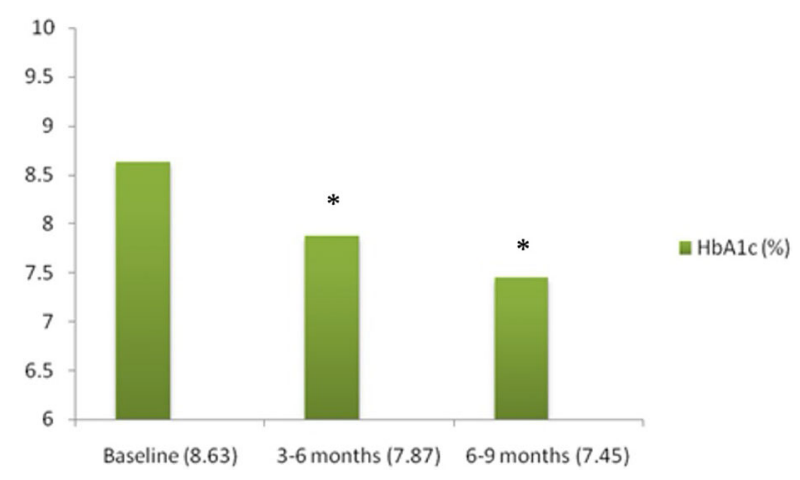

Fig. 3 Mean glycated hemoglobin during the study. HbAlc glycated hemoglobin; ${ }^{*} p<0.01$ vs. previous visit

after a mean period of $4.5 \pm 1.0$ months, and at $\mathrm{V} 2$ in comparison to $\mathrm{V} 1$ after the mean total follow-up period of $8.6 \pm 1.6$ months (Fig. 3). The binary logistic regression analysis accessing an association of examined variables on reaching a target HbA1c showed that various characteristic of patients (age, BMI, duration of T2DM, and comorbidities) did not significantly influence attained HbA1c, although female sex $(p<0.05)$ and higher prandial total daily dose at inclusion $(p<0.01)$ were linked to a lower likelihood of attaining HbA1c $<7.0 \%$.

Among the secondary objectives, the proportion of patients reaching HbA1c goal $<7.0 \%$ (Fig. 4a) and individual HbA1c targets set by physician (Fig. 4b) were significantly higher at V2 in comparison to V1. Additionally, the 
A

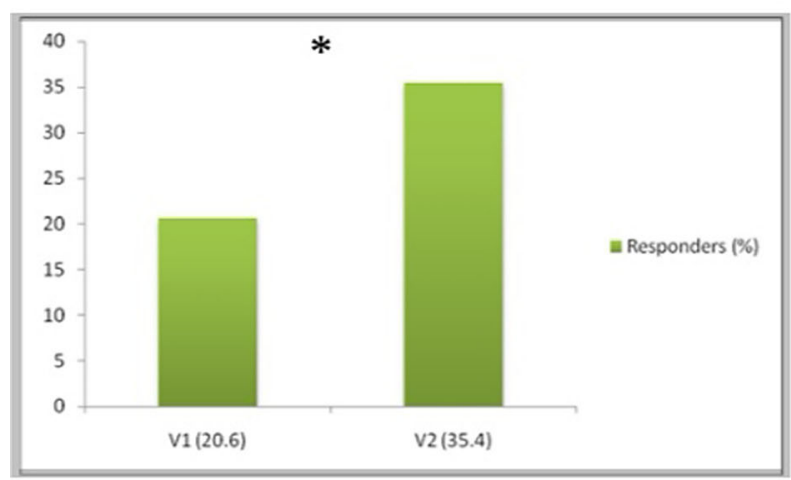

B

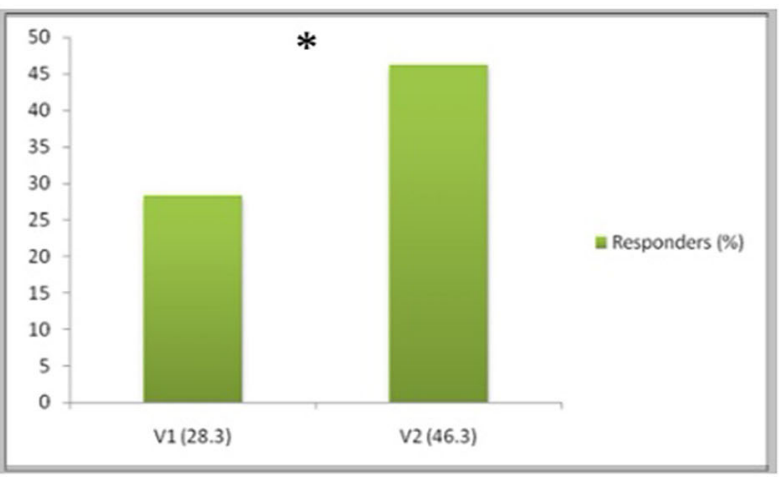

Fig. 4 Proportion of patients reaching target value of glycated hemoglobin (HbA1c). a Responder rate for HbAlc $<7.0 \%$. b Responder rate for individual $\mathrm{HbAlc}$ target. ${ }^{*} p<0.01$ vs. previous visit

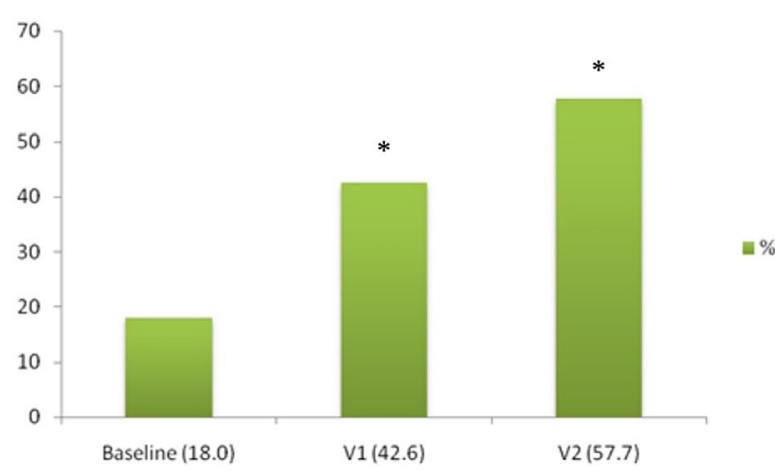

Fig. 5 Proportion of patients reaching fasting plasma glucose $4.4-7.2 \mathrm{mmol} / \mathrm{l} .{ }^{*} p<0.01$ vs. previous visit

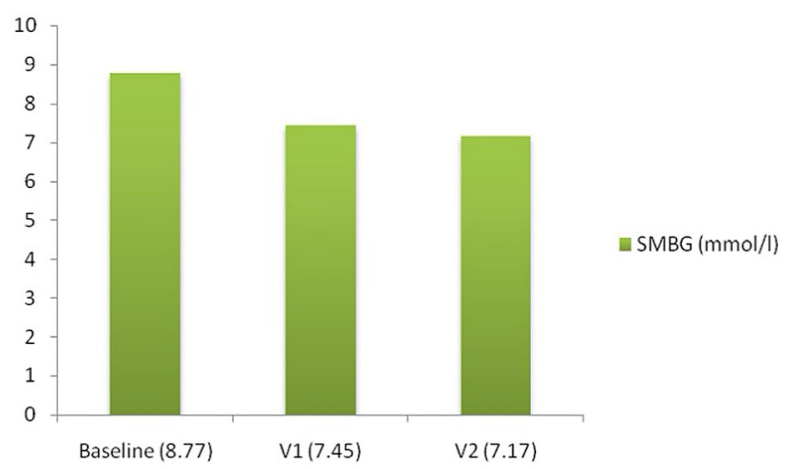

Fig. 6 Mean fasting self-measured blood glucose (SMBG) during the study

proportion of patients with FPG in the range of 4.4-7.2 $\mathrm{mmol} / \mathrm{l}$ was significantly higher at V1 in comparison to baseline, and at V2 in comparison to V1 (Fig. 5). FPG decreased significantly at each visit after the Gla-300 initiation, from $9.62 \pm 3.43 \mathrm{mmol} / \mathrm{l}$ at baseline to $7.98 \pm 2.44$ $\mathrm{mmol} / \mathrm{l}$ at $\mathrm{V} 1$, and to $7.53 \pm 2.20 \mathrm{mmol} / \mathrm{l}$ at $\mathrm{V} 2$ $(p<0.01$ vs. each previous visit). Also, fasting SMBG (three recorded values) significantly decreased at each visit compared to the previous one ( $p<0.01$ vs. previous visit) (Fig. 6).

At the same time, BW was significantly lower at V2 $(86.64 \pm 15.76 \mathrm{~kg})$, but not at V1 $(87.09 \pm 15.87 \mathrm{~kg})$ in comparison to baseline $(87.16 \pm 15.98 \mathrm{~kg})(p<0.05)$, in spite of the significant increase in daily dose of Gla-300 at each of the visits (baseline, $32.27 \pm 14.48$ U/day; $\quad \mathrm{V} 1, \quad 35.98 \pm 16.04 \quad \mathrm{U} /$ day; $\mathrm{V} 2$, $38.27 \pm 16.82 \mathrm{U} /$ day $) \quad(p<0.01$ vs. previous visit), and the increment in proportion of patients requiring prandial insulin (before Gla300 initiation, 45.1\%; at baseline, 58.0\%; at V1, $60.2 \%$; at V2, 62.2\%; $p<0.01$ vs. before Gla-300 initiation). Out of the patients who received premix insulins before initiation of Gla-300, $46 \%$ also had a prandial insulin initiated at the same time as Gla-300 initiation (basal/bolus or basal plus regime).

The main reasons for initiating Gla-300 therapy reported by treating physicians were drug effectiveness (84\%) and the expectation of a lower risk of hypoglycemia (82\%).

As far as Gla-300 titration algorithms are concerned, the most frequently used was dose increments by $2 \mathrm{U}$ every 3-4 days (until target FPG is reached) based on three consecutive mornings' SMBG measurements $(76.3 \%$ at Gla- 
300 introduction, $67.7 \%$ at $\mathrm{V} 1$, and $61.4 \%$ at V2), dose increments by $3 \mathrm{U}$ or $6 \mathrm{U}$ once weekly (until target FPG is reached) based on three consecutive mornings' SMBG measurements (20.3\% at Gla-300 introduction, $18.3 \%$ at V1, and $20.3 \%$ at V2), while other algorithms were used among 3.4\% at Gla-300 introduction, 3.4\% at V1, and $0.9 \%$ at V2. At V1, $10.6 \%$ patients did not follow titration algorithms anymore, while this proportion increased to $17.4 \%$ at V2. The continual reduction in HbA1c became visible after splitting patients according to different titration algorithms, at any point during the study. Patients that had continued titration at V1 had a further significant reduction in HbA1c level at V2 $(8.66 \pm 1.43 \%$ at Gla-300 introduction, $7.90 \pm 1.14 \%$ at $\mathrm{V} 1$, and $7.44 \pm 1.03 \%$ at V2; $p<0.01$ ), compared to patients without titration at V1, who had significant reduction only at V1, without further decrease of HbA1c level at V2 $(8.31 \pm 2.17 \%$ at Gla-300 introduction, $7.52 \pm 1.06 \%$ at $\mathrm{V} 1$, and $7.50 \pm 1.23 \%$ at V2).

Comparing to the period within 3 months prior to Gla-300 initiation there was a significant reduction in the proportion of patients experiencing hypoglycemic episodes and all hypoglycemic events $(p<0.01)$ (symptomatic, $86.3 \%$ vs. $29.1 \%$; confirmed, $81.7 \%$ vs. $24.9 \%$; nocturnal, $45.4 \%$ vs. $8.0 \%$; severe, $20.6 \%$ vs. $0.3 \%)$.

Eighteen patients experienced a total of 19 AEs during the study period. Headache occurred in three patients, with the remaining 16 events occurred only once. Sixteen of the events were resolved, and the remaining two events were stabilized and one was recovering. One event was possibly related to the study drug. Seven events were mild, eight were moderate, and four were severe. Three events were serious and 16 were non-serious AEs. Overall, three patients were hospitalized during the study period (one due to hypoglycemia, one due to myocardial infarction, and one due to acute cholecystitis).

\section{DISCUSSION}

Effectiveness and safety of Gla-300 in patients with T2DM inadequately controlled with different basal or premix insulin therapy regimes were determined through the change in HbA1c, proportion of patients reaching target HbA1c, FPG, and occurrence of hypoglycemia and adverse events from the first day of Gla-300 initiation to the end of the observational period. The enrolled patients had similar baseline characteristics as described in the large EDITION 2 trial [12]. In another study, enrolling real-world patients with T2DM switching from first- to second-generation basal insulin analogues (DELIVER D+ study), similar gender and age distribution, proportion of patients with comorbidities, and prevalence of obesity were registered [13].

The clinical efficacy of Gla-300 in patients with T2DM was shown in four phase III studies: EDITION 1, EDITION 2, EDITION 3, and EDITION JP 2 [12, 14-16]. In our conducted study, switching to Gla-300 in patients previously uncontrolled on different basal or premix insulin regimes showed significant improvement in quality of glucoregulation. In terms of effectiveness, the reduction in HbA1c level, proportion of patients reaching HbA1c $<7.0 \%$, reduction in FPG, and fasting SMBG is similar to the other large studies such as EDITION 2 [12], DELIVER D+ [13], and EDITION 1 [14].

Treatment with Gla-300 was associated with a decreased risk of experiencing at least one confirmed or severe nocturnal hypoglycemic event. Gla-300 demonstrated lower risk of hypoglycemia during the night and at any time of day in EDITION 2 [12], and lower risk of nocturnal hypoglycemia in EDITION 1 [14] in comparison to Gla-100. The rate of AEs in this study was low and comparable to safety data from other Gla-300 trials [12, 14]. A metaanalysis of safety data from the EDITION trials revealed reductions in the rates of confirmed or severe hypoglycemia with a $14 \%$ rate ratio difference of hypoglycemia at any time favoring the Gla-300 formulation [17].

The daily dose of basal insulin increased significantly in this study in line with the results from EDITION $2 \quad(0.64 \pm 0.22$ to $0.92 \pm 0.31 \mathrm{U} / \mathrm{kg} /$ day) [12] and EDITION 1 $(0.67 \pm 0.29$ to $0.97 \pm 0.37 \mathrm{U} / \mathrm{kg} /$ day) [14]

The main limitation of this study is the observational design and short follow-up 
period. In addition, since enrolled patients have relatively long duration of disease and length of prior insulin therapy, extrapolation of the study conclusions to patients with T2DM with shorter disease duration remains questionable. Finally, the lack of patients using novel antidiabetic medications does not allow the proper assessment of the performance of Gla-300 in various novel antidiabetic therapy algorithms.

\section{CONCLUSIONS}

This prospective, observational, single-arm, multicenter, real-world study conducted in Serbia, among patients with T2DM previously uncontrolled on different basal or premixed insulin therapy regimes, provides valuable clinical insight into both the effectiveness and safety of Gla-300 in a local real-life setting. The introduction of Gla-300 significantly improved glycemic control after a mean follow-up period of 8.6 months regardless of applied basal insulin titration algorithm, with active patient engagement in the titration period being one of the most important factors in the success of Gla-300 therapy initiation. Finally, the uptitration of its dose did not increase the risk of hypoglycemia, providing evidence that Gla-300 is easy to titrate with a low risk of hypoglycemia and other AE.

\section{ACKNOWLEDGEMENTS}

We thank the participants of the study and all investigators who contributed to patient recruitment and data collection.

Funding. Sponsorship for this study and journal's Rapid Service Fee were funded by Sanofi Serbia.

Authorship. All named authors meet the International Committee of Medical Journal Editors (ICMJE) criteria for authorship for this article, take responsibility for the integrity of the work as a whole, and have given their approval for this version to be published. All authors had full access to all of the data in this study and take complete responsibility for the integrity of the data and accuracy of the data analysis.

Authorship Contributions. Milena VelojicGolubovic: data analysis and interpretation, drafting publication, critical revision, final approvals, accountable for accuracy and integrity. Vojislav Ciric: data analysis and interpretation, drafting publication, critical revision, final approvals, accountable for accuracy and integrity. Marija Dimitrijevic: data analysis and interpretation, critical revision, final approvals, accountable for accuracy and integrity. Tijana Kovic: concept and design, data analysis and interpretation, critical revision, final approvals, accountable for accuracy and integrity. Milica Mitic: data acquisition, data analysis and interpretation, drafting publication, critical revision, final approvals, accountable for accuracy and integrity. Biljana Olujic: data acquisition, data analysis and interpretation, drafting publication, critical revision, final approvals, accountable for accuracy and integrity. Natasa Pevac: data acquisition, data analysis and interpretation, drafting publication, critical revision, final approvals, accountable for accuracy and integrity. Sasa Radenkovic: data analysis and interpretation, drafting publication, critical revision, final approvals, accountable for accuracy and integrity. Danijela Radojkovic: data analysis and interpretation, drafting publication, critical revision, final approvals, accountable for accuracy and integrity. Selena Vukadinovic: data analysis and interpretation, drafting publication, critical revision, final approvals, accountable for accuracy and integrity. Djordje S. Popovic: data analysis and interpretation, drafting publication, critical revision, final approvals, accountable for accuracy and integrity.

List of Investigators. Dusica Toljic-Suluburic, MD, General Hospital, Cacak, Serbia; Koviljka Vulovic, MD, General Hospital, Cacak, Serbia; Dragana Udovicic, MD, General Hospital, Uzice, Serbia; Klara Lelik-Tubic, MD, Medical Center, Alibunar, Serbia; Snezana Marinkovic, MD, General Hospital, Pirot, Serbia; Milica Mitic, MD, General Hospital, Cuprija, 
Serbia; Jasmina Stojanovic, MD, General Hospital, Cuprija, Serbia; Rada Milosavljevic, MD, General Hospital, Cuprija, Serbia; Gordana Milosevic, MD, General Hospital, Leskovac, Serbia; Snezana Stojanovic, MD, General Hospital, Leskovac, Serbia; Milan Zivkovic, MD, General Hospital, Leskovac, Serbia; Branislava Radosavljevic, MD, General Hospital, Bor, Serbia; Dusan Jerinkic, MD, General Hospital, Kikinda, Serbia; Klara Nemet-Tucic, MD, General Hospital, Subotica, Serbia; Suzana SabanTrnokopovic, MD, Medical Center "Dr Janos Hadzi", Backa Topola, Serbia; Vesna Vukelic, MD, Medical Center "Dr Janos Hadzi", Backa Topola, Serbia; Sonja Mrdovic, MD, General Hospital "Dr Laza K. Lazarevic", Sabac, Serbia; Olgica Stanic-Bugarcic, MD, General Hospital "Dr Laza K. Lazarevic", Sabac, Serbia; Dragana Stojcic, MD, General Hospital "Sveti Luka", Smederevo, Serbia; Katarina Odanovic, MD, General Hospital, Valjevo, Serbia; Radmila Velickovic, MD, General Hospital "Stefan Visoki", Smederevska Palanka, Serbia; Zorica Djuric, MD, General Hospital, Loznica, Serbia; Dafina Ristic, MD, General Hospital, Pancevo, Serbia; Natasa Pevac, MD, General Hospital, Sremska Mitrovica, Serbia; Biljana Olujic, MD, General Hospital "Dr Radivoj Simonovic", Sombor, Serbia; Nikola Sretenovic, MD, General Hospital, Pozarevac, Serbia; Dejan Stojanovic, MD, General Hospital, Petrovac na Mlavi, Serbia.

Disclosures. Milena Velojic-Golubovic declares associations (Lecturer, Clinical Trial Investigator) with the following companies: AstraZeneca, Boehringer-Ingelheim, Eli Lilly, Novo-Nordisk, and Sanofi-Aventis. Vojislav Ciric declares association (Lecturer and Clinical Trial Investigator) with the following companies: Boehringer-Ingelheim, Novo-Nordisk, and Sanofi-Aventis. Marija Dimitrijevic and Tijana Kovic are Sanofi employees. Milica Mitic declares association (Congress sponsorship) with the following companies: AstraZeneca, Boehringer-Ingelheim, Novo-Nordisk, and Sanofi-Aventis. Biljana Olujic declares associations (Lecturer, Clinical Trial Investigator) with the following companies: AstraZeneca, BerlinChemie, Novo-Nordisk, and Sanofi-Aventis.
Natasa Pevac declares associations (Lecturer) with the following companies: AstraZeneca, Eli Lilly, Merck, Novo-Nordisk, and Sanofi-Aventis. Sasa Radenkovic declares associations (Lecturer, Clinical Trial Investigator) with the following companies: AstraZeneca, Merck, Novo-Nordisk, and Sanofi-Aventis. Danijela Radojkovic declares associations (Lecturer, Member of the Advisory Board, Clinical Trial Investigator) with the following companies: AstraZeneca, Boehringer-Ingelheim, Novo-Nordisk, and SanofiAventis. Selena Vukadinovic declares associations (Lecturer) with the following companies: Eli Lilly and Sanofi-Aventis. Djordje S. Popovic declares associations that might represent the conflict of interest with the following companies: Abbott, Alkaloid, AstraZeneca, BoehringerIngelheim, Berlin-Chemie, Eli Lilly, Galenika, Krka, Merck, Novo Nordisk, PharmaSwiss, Sanofi-Aventis, Servier, and Worwag Pharma.

Compliance with Ethics Guidelines. The study was approved by the Ethics Committee of Republic of Serbia and Regulatory authority (ALIMS) in Serbia, and all procedures were in accordance with the ethical standards of the 1964 Helsinki Declaration and its later amendments or comparable ethical standards. All the participants provided written informed consent to include their information in anonymous, aggregated analyses for this study.

Data Availability. The data sets during and/ or analyzed during the current study are available from the corresponding author on reasonable request.

Open Access. This article is licensed under a Creative Commons Attribution-NonCommercial 4.0 International License, which permits any non-commercial use, sharing, adaptation, distribution and reproduction in any medium or format, as long as you give appropriate credit to the original author(s) and the source, provide a link to the Creative Commons licence, and indicate if changes were made. The images or other third party material in this article are included in the article's Creative Commons licence, unless indicated otherwise in a credit line to the material. If material is not included 
in the article's Creative Commons licence and your intended use is not permitted by statutory regulation or exceeds the permitted use, you will need to obtain permission directly from the copyright holder. To view a copy of this licence, visit http://creativecommons.org/licenses/bync/4.0/.

\section{REFERENCES}

1. UK prospective Diabetes Study (UKPDS) Group. Intensive blood glucose control with sulphonylureas or insulin compared with conventional treatment and risk of complications in patients with type 2 diabetes (UKPDS 33). Lancet. 1998;352: 837-53.

2. American Diabetes Association. Pharmacologic approaches to glycemic treatment: standards of medical care in diabetes-2020. Diabetes Care. 2020;43(Suppl 1):S98-110.

3. Brown J, Nichols G, Perry A. The burden of treatment failure in type 2 diabetes. Diabetes Care. 2004;27:1535-40.

4. Owens DR, Matfin G, Monnier L. Basal insulin analogues in the management of diabetes mellitus: what progress have we made? Diabetes Metab Res Rev. 2014;30:104-19.

5. Korytkowski M. When oral agents fail: practical barriers to starting insulin. Int J Obes Relat Metab Disord. 2002;26(Suppl 3):S18-24.

6. Cryer PE. The barrier of hypoglycemia in diabetes. Diabetes. 2008;57:3169-76.

7. Carver C. Insulin treatment and the problem of weight gain in type 2 diabetes. Diabetes Educ. 2006;32:910-7.

8. American Diabetes Association. Glycemic targets: standards of medical care in diabetes-2020. Diabetes Care. 2020;43(Suppl 1):S66-76.

9. Garber AJ, Abrahamson MJ, Barzilay JI, et al. AACE/ ACE comprehensive diabetes management algorithm 2015. Endocr Pract. 2015;21:438-47.
10. Imran SA, Agarwal G, Bajaj HS, Ross S. Diabetes Canada 2018 clinical practice guidelines for the prevention and management of diabetes in Canada: targets for glycemic control. Can J Diabetes. 2018;42(Suppl 1):S42-6.

11. Becker RH, Dahmen R, Bergmann K, Lehmann A, Jax T, Heise T. New insulin glargine 300 Units $\mathrm{mL}^{-1}$ provides a more even activity profile and prolonged glycemic control at steady state compared with insulin glargine 100 Units $\mathrm{mL}^{-1}$. Diabetes Care. 2015;38:637-43.

12. Yki-Jarvinen $H$, Bergenstal $R$, Ziemen $M$, et al. New insulin glargine 300 units $/ \mathrm{mL}$ versus glargine 100 units/mL in people with type 2 diabetes using oral agents and basal insulin: glucose control and hypoglycemia in a 6-month randomized controlled trial (EDITION 2). Diabetes Care. 2014;37:3235-43.

13. Sullivan SD, Bailey TS, Roussel R, et al. Clinical outcomes in real-world patients with type 2 diabetes switching from first- to second-generation basal insulin analogues: comparative effectiveness of insulin glargine 300 units $/ \mathrm{mL}$ and insulin degludec in the DELIVER D+ cohort study. Diabetes Obes Metab. 2018;20:2148-58.

14. Riddle $\mathrm{M}$, Bolli GB, Ziemen $\mathrm{M}$, et al. New insulin glargine 300 units/mL vs. glargine 100 units $/ \mathrm{mL}$ in people with type 2 diabetes using basal and mealtime insulin: glucose control and hypoglycemia in a 6-month randomized controlled trial (EDITION 1). Diabetes Care. 2014;37:2755-62.

15. Bolli GB, Riddle MC, Bergenstal RM, et al. New insulin glargine $300 \mathrm{U} / \mathrm{ml}$ compared with glargine $100 \mathrm{U} / \mathrm{ml}$ in insulin-naive people with type 2 diabetes on oral glucose-lowering drugs: a randomized controlled trial (EDITION 3). Diabetes Obes Metab. 2015;17:386-94.

16. Terauchi Y, Koyama M, Cheng X, et al. Glycemic control and hypoglycemia in Japanese people with $\mathrm{T} 2 \mathrm{DM}$ receiving new insulin glargine $300 \mathrm{U} / \mathrm{mL}$ in combination with OADs (EDITION JP 2) [abstract no. 94-LB]. Diabetes. 2014;63(Suppl 1A):LB24.

17. Ritzel R, Roussel R, Bolli GB, et al. Patient-level meta-analysis of the EDITION 1, 2 and 3 studies: glycaemic control and hypoglycaemia with new insulin glargine $300 \mathrm{U} / \mathrm{ml}$ versus glargine $100 \mathrm{U} / \mathrm{ml}$ in people with type 2 diabetes. Diabetes Obes Metab. 2015;17:859-67. 